\title{
Trauma Informed Practice: Increasing Awareness for Pre-Service School Counselors
}

\author{
Mary Ann Hollingsworth, PhD \\ University of West Alabama, United States
}

Doi: 10.19044/ejes.s.v6a8

URL:http://dx.doi.org/10.19044/ejes.s.v6a8

\begin{abstract}
Life challenges and traumas come in many forms and the capacity to bounce back, adapt, and move on to a new normal also comes in many forms. This study examined some common life challenges and trauma experiences and how persons in these have reacted and grown past the experiences. The study also used action research to provide graduate student counselors insight on facets of trauma that they could help with in service as counselors.The study was conducted by 102 school counseling and clinical mental health counseling students in a graduate level Lifespan Development course with volunteers selected by them to share through interview impact of challenges and resilience formation in the challenge areas of Substance Addiction; Habit Addiction; Disabilities; Natural Disaster Trauma; Combat Trauma; Other Individual Trauma such as a House Fire, Domestic Violence, Child Sexual Abuse, or Severe Accident; Community Event; Couple Event; Family Event; or School Event. The volunteers shared description of the life challenge or trauma; whole person reactions to the event from immediate to current reaction (at least a year post-event); life factors pre-event that may have contributed to the occurrence of the event or compounded recovery from the event; and life factors both pre- and post-event that helped with recovery from the event. The graduate students then synthesized answers to frame potential pathways to explore further for enhancement of resilience building with future clients and students and to support students in recovery and healing from trauma experiences while in their schools.
\end{abstract}

Keywords: Graduate educator student training in trauma, Children and trauma, post traumatic growth, resilience development.

\section{Introduction}

Attention to traumatic events in the lives of students tends to focus on single events that could be categorized as acute trauma, much as a singular occurrence of a physical illness element such as a case of flue or a broken leg 
from an accident. Wamser-Nanney and Vandenburg (2013) noted the commonality of repeated events of trauma for many children and adolescents as well as presence of ongoing impact from the same trauma experience as prolonged trauma (p. 671). Often this chronic trauma was described as interpersonal and having onset in childhood. As such, manifestations would be presented in the context of school. Wamser-Nannery and Vandenburg noted such symptoms as lowered self-regulation of behavior, attention, and impulses and problems with socialization or self-identity.

An emerging focus for educators is encouragement of TraumaInformed Practices (TIPs) in the classroom. Banks and Meyer (2017) supported this focus through classroom dialogue between pre-service teachers and a mental health therapist who worked with students experiencing chronic life trauma. This experience increased awareness for the respective preservice teachers and also helped the authors to more firmly identify needed components of TIPs training for educators.

Engebretson and Weiss (2015) noted that in the face of traumatic experiences for students such as a community act of violence or a student's death, there is still expectation for school to continue amidst the distress and disturbance of these events upon all members of a school and its community. Engebretson and Weiss examined potential for inclusion of attention to these topics and events within the routine curriculum of teaching for the school. They contended that to do so would support students in a healing process of dealing with the trauma versus pushing it to the side for "school." This inclusion can consist of time to ask questions, attain more knowledge, or do subject related work that integrates facet of the trauma.

\section{Literature Review}

Considerable research exists which describes impact of trauma on children. Less research is available on educator intervention within presence of student trauma. Research in both areas is important for further support of integration of trauma informed practice within faculty and staff of P12 schools. Knowledge of such research can enhance efficacy of educator preparation in their pre-service training programs.

\section{Trauma Impact on Children}

When students enter the doors of a school and classroom, they do not check "life" at the door much as forbidden items are checked for airline passengers before flight. Thus students bring into school with them the impact of life trauma that then moves beyond the individual student to also influence fellow students, faculty, and staff. Villenas (2018) reflected on her experience as both a community member and a teacher during the 1992 Los Angeles riots with the Rodney King beating. Vellenas reflected "How were we supposed to 
as if it was business as usual? How were we supposed to face our young students and pretend that their education was divorced from the conditions that were criminalizing and devastating their communities?"(p. 110).

Day et al. (2015) describe the multiple demands needed for success in school and stress on these per student experience of chronic trauma. All students have demands for attention, comprehension, memory, organization, and self-regulation (p. 1088). Day et al. noted that much research has supported evidence of trauma impact on diminished academic performance and reduced social-emotional efficacy. Examples are lower rate of homework completion and greater rates of suspension or expulsion from school. One of the most frequent settings of this chronic

Thompson and Schwartz (2014) conducted a phenomenological student with young men of color to specifically examine the question of effect of trauma on their learning engagement and access to counseling and support services. The findings indicated that Posttraumatic Stress (PTS) was considered to be life as normal - often daily, ongoing series of experiences ( $\mathrm{p}$. 50). The study participants considered trauma to be a given component of life and even felt ownership beyond the daily trauma of individual self to the collective trauma of others like them currently or in the past who were also caught in similar trauma experiences such as poverty or environments of violence.

Experiences of trauma, whether acute or chronic, render impact on observable behavior of trauma victims. Meshcheryakova (2012) noted a tendency of trauma victims to feel compelled to repeat painful past experiences as an attempt to master them - a concept first espoused by Sigmund Freud (p. 50). This repetition was described as a two-phase process with the first phase consisting of re-experience of past sensations in a current context. The second phase was a re-experience of defensive reactions with a purpose to avoid going through such an experience again. Meshcheryakova indicated that such re-experiencing did not serve a beneficial role, but rather promoted a re-victimization of the person with even potential for negative fallout toward others within the person's current environment.

One experience of chronic trauma is that of war. While some countries have active war on the ground in the villages and cities where youth live, many other children experience traumatic impact from deployment of a family member to military service in a combat location somewhere other than the home community or perhaps even the home country. This is true for many children in the United States who have family members deployed into combat via service in the military Reserves or National Guard. Heide, Mooren and Kleiber (2016) noted that ,the experience of war has been central to establishment of a distinction between rather delineated traumatic events such as a robbery, disaster, or traffic accident and more complicated traumatic 
events" (p.2). Heide, et al. suggest differentiation in treatment so that it is phased to accomodate safety, reduction of symptoms, and acquisition of skills before moving on to work with traumatic memories and then psychological and social reintegration

Childhood trauma experiences are sometimes results of environmental factors external to a home. However, chronic trauma can also live within the home within family or care-giving relationships. Becker-Weidman (2009) indicated that early childhood maltreatment could foster developmental deficits, particularly in ,communication, daily living skills, and socialization“ (p. 137). Becker-Weidman noted that the components of this trauma often included emotional abuse, neglect, sexual abuse, physical abuse, and witnessing of domestic violence (p. 138). These experiences were noted to foster deficits in mutiple realms of current personal functioning and also to foster potential adult reduced functioning in multiple facets of health, especially psycholoical health.

Reinbergs and Fefer (2017) firther confirmed the impact of homebased trauma on the educational experience of children. They shared several U.S. national level statistics that emphasize concern. For example, one in eight children are reported to experience substantiated maltreatment by age 18 and an estimated cost per year for treatment of just one case of maltreatment to be $\$ 210,000$ with some of that spent on services via placement in special needs education (p. 250). Reinbergs and Fefer noted that children are often influenced by additional trauma events such as natural disasters or community violence.

Bell, Limberger, and Robinson,. (2013) provided depth of detail on symptoms that can be presented by child victims of trauma, many of which are presented in the context of school. Some examples given on page 141 are physical symptoms of recurring physical complaints, above normal state of alertness, and sudden gain or loss of weight Examples of behavioral symptoms were social isolation, increased risk-taking, increased attentionseeking, increased aggresson, or regression to previous developmental behavior. Emotional symptoms that could present at school were difficulty with emotional regulation, fear, or lack of self-confidence. Finally cognitive symptoms include inability to focus, learning disabilities or poor skill development, and changed attitudes about people and the student's future.

\section{Intervention with Chronic Trauma in Youth}

Chronic trauma often has seemingly silent but pervasive impact. Ferentz (2015) notes that one impact is self-destructive behavior that is present, but not obviously evident in the earlier stages of trauma experience. Ferentz presents a cycle of self-destructive behavior that begins with the initial triggering traumatic event as well as those following life events that trigger re- 
experiecing the trauma. This cycle moves through inner negative thinking and feelings such as tension and anxiety to outward behavior that is harmful toward self. Educators are most apt to observe the self-destructive behavior and awareness of the etiology can promote appropriate support to students caught in a cycle of chronic trauma.

While it is important for intervention by clinicians or educators to help ameliorate trauma impact, a greater service is rendered to victims of trauma when there is concurrent support in development of resilience. This resilience can help the healing process, enhance post-traumatic growth, and better empower youth for all of life's challenges. Steele and Malchiodi (2012) defined resilience as adaptation toward competence with thinking and acting in the presence of distressful experiences. They noted that with the chronic vicarious exposure to trauma via media and in some cases increased presence of face-to-face trauma, building resilience has become more universally challenging.

Steele and Malchiodi (2012) listed ten protective factors that are a part of building and maintaining resilience. Several of these could be supported through educator interevention. The first factor was Optimisim - maintenance of a postive mindset on life helps people to bounce back from life's challenges. Educators can practice general optimism in daily work. Another relevant factor was that of a Role Model - as educators practice resilient living themselves, students can naturally follow their leadership. The factor of Social Supports is an integral component of school as students engage with peers as well as school personnel. A key in making this a positve factor is for educators to take time to „be there" when needed to support students through a listening ear or appropriate referral. Finally, an important component is Training in development of resilience. This can be enhanced for educators through educator preparatory training at the collegiate level and through educator professional development training in the school setting.

\section{Educator Intervention for Presence of Student Trauma}

While society's infrastructure of care has support usually available for immediately post-trauma event, Bath (2015) notes that more attention to comprehensive support is needed for the hours of the day after the initial emergency room, mental health therapist session, etc. are completed. The trauma impact goes with the individual into home, school, community, etc. Bath recommends attention to three factors to support healing and resilience building in these daily non-clinical settings (p. 6). The first factor is creation of a Safe Environment in which an individual can feel secure and calm. The second factor is to foster and maintain connections with caring others to support need for belonging and resilience building. The third factor is Coping 
which strengthens the individual's need to experience mastery of life walk and independence.

Blaustein and Kinniburgh (2010) noted that when working with youth experiencing trauma, the ultimate goal is "to build their capacity to harness internal and external resources in service of effective and fulfilling navigation of their life, across domains of functioning" (p. 209). Both past and present experience could interfere with optimal development and functioning in all personal life areas. While much of the recommendations shared by Blaustein and Kinniburgh apply to clinical treatment, much could also be effective within routine educator practice at school. An example is helping youth to build a self-reflective process to observe and explore self's behavior, feelings, and thoughts that could be related to past experiences.

Shu-chin and Pope (2019) note that this self-reflection has been a crucial component in past core roles of educators as they facilitated student learning about life values within self and application of these outward in daily living. Shu-chin and Pope also note that today's focus of educators is more reduced to targeted vocational training. A prime example of this is the common practice of public high schools in the United States having tracks for students in Academic Preparation (AP) for college attendance and VocationalTechnical training for students who will follow an immediate path of workforce entry after high school.

Another arena that Blaustein and Kinniburgh (2010) recommend in the treatment process for youth and trauma is enrichment of the capacity for selfregulation for here and now distress of the moment. Many student behaviors that result in some type of school-based discipline are influenced by deficit in capacity of students to manage this current moment distress. Examples are instant reaction to bullying or distraction from staying on task in the classroom. Blaustein and Kinniburgh recommend skill development training for children such as problem-solving skills and goal setting with follow-up reinforcement of these through reminders and positive verbalization to students when these skills are practiced. This skill development training could help students universally in the context of academic endeavor.

Thompson and Schwartz (2014) provided some suggestions for educators to enhance engagement of learning for young men of color who might be caught in life trauma of poverty of environmental violence. Provision of a safe space such as time for group discussion was considered a first step as this would empower students to find mutual support and a sense of not being alone in their routine of daily trauma. A next step was to encourage and support remembrance of traumatic events and permission to grieve over impact. This confrontation of the reality was considered crucial within a healing process. The last step was termed Reconnection and included 
a sense of a new normal of self- identity, new framework of relationships, and even some new beliefs and meaning.

Reinbergs, E.J. \& Fefer, S.A. (2017) discussed increased integration of TIPs within the school setting as more school counselors, psychologists, and social workers have been hired as routine staff. Examples of improved support are Multitiered Systems of Support (MTSS) and Response to Intervention (RTI) Both of these blend delivery of academic, behavioral, and mental health services to support better development for the whole of a student - not just the capacity for academic achievement. Reinbergs and Fefer noted that while progress is being made to support greater integration of TICs into MTSS and RTI, a need continues for more research and work with both what could support implementation of school-based trauma services as well as those barriers to this implementation.

Bullying has become a chronic trauma event for many students in elementary through high school levels. Long-term effects are noted in incidents such as school shootings where the back-story of the perptrators included previous victimization from bullying. Jenkins, Fredrick, and Wenger (2017) studied responses of 656 students in third to eight grade on mediation of either peer support or teacher support between victimization status and social, emotional, and behavioral difficulties. Their findings are a strong message for increased focus on educator intervention with this particular form of chronic trauma.

Jenkins, et al. found that participant perceived teacher support was strongest in the earlier elementary school years and tapered down as a student moved into pre-adolescence and adolescence. While this is mirrored in developmental parameters of adolesecence, the study found that teacher support was an important component of mattering for social-emotional outcomes for bullying victims in combination with presence of either parent or peer support. The study confirmed a strong relationship between peer support and mediation of various difficulties for victims of bullying. The message for educators in this is intervention to encourage peer support in healthy ways within the context of school. Examples are participation in extracurricular activities such as sports or student organizations and opportunities for group work in class assignments.

Day et al. (2015) conducted a pilot study of a curriculum that was designed to increase TIPs in educational settings. The study was based on a modification of the curriculum The Heart of Teaching and Learning: Compassion, Resiliency, and Academic Success. This was described as ,an integrated, manualized curriculum based on research, theory, and clinical practice and is grounded in ecological and attachment theories applied using psychoeducational, cognitive-behavioral, and relational approaches." (p. 1091). The six modules of the curricullum were (1) background and 
definitions of trauma, (2) compassionate schools and survival, (3) self-care, (4) curriculum domains and specific strategies, (5) collaborative problem solving, and (6) role plays, games, and case vignettes.(p.1092). Results of the pilot implementation of the curriculum indicated a decrease in trauma symptoms exhibited by participating students who were all court-ordered youth in residential treatment placement.

Currently in the United States and historically within many countries, educators work with students who are refugees or whose families have chosen to geographically relocate to another country for various reasons. Heide, et al. (2016) addressed treatment of complex or chronic trauma impact where youth and adults were refugees per occurrence of war. As noted earlier, many factors of the phased treatment for complex trauma recommended by Heide, et al. can be well-supported in an educational setting. As youth spend much of their time in a school setting, this can be maintained as a place of safety, opportunity to learn new skills, and a key setting for psychological and social integration as therapeutic intervention moves to completion.

While focus has increased on what educators can do in responsive intervention to help with chronic trauma for students, Langley, Santiago, Rodriguez, and Zelaya, (2013) discussed the need for more early intervention to help build resilience and prevent detrimental impact of trauma experience on normal development of youth. Langely, et al. noted that for youth who receive mental health care, seventy five percent of this is through the education sector (p. 248). This framework seems to foster positive collaboration between student, family, community, and school in not only helping the student, but also promoting enhanced collaborative efficacy among the education stakeholders.

\section{Implications for Pre-Service Educator Training Programs}

Beneficial intervention starts with awareness of the need for intervention with accompanying etiology and symptoms. This awareness can then serve as a foundation for effective intervention to resolve or manage presenting limitations for academic and personal success. Bell, et al. (2013) noted that ,certain at-risk behavior patterns are associated with childhood traumatic experiences and educators are seeing an increasing responsibility to identify and address symptoms associated with childhood trauma as they fulfill an evolving role for shaping developmental needs of their students."(p.140).

Bell, et al. (2013) indicated the vital role of educators to support traumatized children ,either individually or through a school-wide approach."(p.142) - citing a statistic from Jaycox, et al. (2010) that 91 percent of children completed trauma treatment based within a school setting as compared to only 15 percent completion in an outpatient mental health setting. 
Three suggestions were given for teacher intervention support, support that could easily be provided within the normal context of the teacher's role. These were (1) Identify trauma symptoms with a student and refer to an appropriate school helping professional such as a counselor or social worker, (2) Participate in a school-based trauma team, and (3) Support traumatized children through the therapeutic process. (p. 142).

Because youth have so much presence under the influence of teachers and other school personnel, educators are in a key position to facilitate development of student resilience and efficacy in response to life trauma. Von der Embse, et al. (2018) noted that even with this high role of influence, educators have considerable challenge with identification of students at risk for problems per influence of life trauma. Educators can also have significant challenge in awareness of how, when, and where to refer students for help with these issues. In the study by Von der Embse, et al., teachers were trained in universal screening protocols to use with students to determine risk level. The study results indicated support by teachers for such an assessment process. The study did not indicate support for this assessment as a duty of the teacher. A key implication was the need for increased educator awareness of risk factors and support for whole child resilience development within the context of school.

Anderson, Blitz, and Saastamoinen (2015) observe that while educators at each level of school faculty and staff are increasingly aware of the pervasive impact of chronic trauma on their students, there is also a challenge with identification of their professional role in the process of management and healing. Anderson, et al. note that a crucial component of effective intervention is collaborative attention to support for student healing through all stakeholders within and outside of the school setting in the process. This strongly suggests awareness and engagement of not only school-based mental health professionals such as counselors, psychologists, or social workers - but also personnel from custodial staff to coaches to teachers to administrators.

A key component of capacity to engage with helping is to first promote awareness of need and effective support for need resolution. Anderson, et al. (2015) conducted a study between a university educator department and local elementary schools to assess potential best practice focus with professional development training for school personnel in assistance for trauma-impacted students. The framework of their research provided a viable framework to also use in pre-service educator training toward capacity to help students impacted by trauma. This framework included the three steps of (1) Needs assessment on key experiences putting students at risk for negative impact on educational pursuit, (2) Professional Development targeted toward knowledge 
and skill development per the needs assessment, and (3) Periodic post training reflection assessment on efficacy of the training.

\section{Methodology}

Using the framework of Anderson, et al. (2015) action-research was conducted in several sections of a graduate degree level professional orientation course for school counselors. The name of the project was Challenges and Resilience Across the Lifespan with a purpose of student exploration of developmental impact on life of crises, disasters, disabilities, and addictive behavior, all of which fit literature parameters for chronic trauma experience. Students interviewed an acquaintance volunteer about a life trauma experience per a list of example trauma events and an interview format from the instructor. Students then wrote reflections on insight gained for both personal application and application as future educators.

\section{Participants}

Participants were 102 students enrolled in a graduate level course on professional orientation for counseling, most of whom were in preparation to be school counselors. While this is an ongoing course assignment, this study was conducted during terms for spring and summer of 2019. Volunteer participants consisted of family, friends, or colleagues known by student participants in their local communities.

\section{Procedure}

In their research, students first selected a volunteer who they knew had been impacted significantly by an area of life trauma (selection list provided by the instructor and further described below in the section on Procedures), obtained agreement of the person for a confidential interview about the experience, and then interviewed the person with a set of questions from the instructor as shared below in the section on Procedures. The second part of the research was to share peresonal reflection on what they learned from the research that they could use in their own personal lives and what they could use in their future work as educators.

\section{Analysis}

Volunteer experiences were selected from a list provided by the instructor to include the areas and frequency of student focus as shown below in table 1 .

Table 1. Traumatic Experience and Frequency of Student Focus

\begin{tabular}{|l|l|}
\hline Type of Experience & Frequency of Student Focus \\
\hline Substance Addiction & 19 \\
\hline Death of Family Member & 14 \\
\hline Domestic or Intimate Partner Violence & 14 \\
\hline Disability from Severe Illness & 12 \\
\hline
\end{tabular}




\begin{tabular}{|l|l|}
\hline Limitations from a Severe Accident & 10 \\
\hline Childhood Abuse & 9 \\
\hline Home Burned in a Fire & 8 \\
\hline Natural Disaster & 7 \\
\hline Divorce in Immediate Family & 3 \\
\hline Combat Trauma & 2 \\
\hline Chronic Rejection by Family of Community & 2 \\
\hline Victim of Chronic Bullying & 1 \\
\hline Incarceration of a Family Member & 1 \\
\hline
\end{tabular}

\section{Data Analysis and Findings}

Volunteers often reported trauma of a different type growing out of the trauma experience of focus. An example was a choice to cope with substance abuse to help with a trauma such as disability from a severe accident. Student written reflections on the research focused on two components.

First was targeted insight from volunteer participants on (1) Reaction to experience, both immediately post event and currently, (2) Pre-event life developmental influences that were both negative and positive, (3) Current post traumatic growth impact from experience, and (4) Advice from volunteer for others regarding such an experience.

Secondly, students shared insight on (1) perceived Pathways of Prevention they could help students with in building resilience protective factors for potential traumatic experiences and (2) perceived Pathways of Recovery they could help students with in healing from the occurrence of a traumatic life experience.

Examples of student reflections are shared below. For sake of space, only one representative student reflection is shared per reflection focus area.

Reaction to experience, both immediately post event and currently. Volunteer was initially devastated after the hurricane. She described feeling overwhelmed with emotions and felt powerless as she had no control over mother nature. Sheis still reeling from the loss she endured after the hurricane but is slowly recovering. She has relocated near home and is receiving support from her family and close friends. The volunteer has also regained contact with family, friends, and coworkers who are still in her local area and speaks to them often. She is sometimes emotional when she sees old and new photos of the local beach, but is overall happy that she has her life. She no longer dwells on "why" it happened and feels confident and hopeful that everything will fall into place.

Pre-event life developmental influences that were both negative and positive. The volunteer seemed to have had many negative life factors that influenced this situation. While he does report having social anxiety enhanced by this situation, he already slightly experienced it before due to 
being "jumped" by his peers after enrolling into a new high school. After returning home from this deployment, his unit would immediately begin a rigorous training cycle and deploy again in six months. During that time he found another service member after committing suicide, was present when a fellow Ranger died from an aneurism and witnessed a helicopter crash during a training event. Also, during this time, his newly wedded wife was hospitalized and diagnosed with Type 1 Diabetes.

Positive life factors that influenced the volunteer would be being raised in a tough manner. His parents taught him that the only way to success would be through hard work and that life is not fair. After this experience, he returned home to get married and later start raising a family. After getting out of the military he attended college, reduced the amount of travel with his work, and forced himself to reintegrate himself into civilian life.

Current post traumatic growth impact from experience. The volunteer gives all credit to personal faith in God for allowing her to move past this tragic event in her life and find peace and happiness again. She reports, "I find peace in knowing that I will see my son again in heaven one day." Linda feels that she has not only grown in her faith but also her self confidence and believing in following her dreams and setting goals. She states she has realized just how short life can be and she wants to make the most of her time left on this earth.

Advice from volunteer for others regarding such an experience. The volunteer's advice to others who experience domestic violence abuse is to SPEAK OUT. Please take pictures of the scars. Her most important advice is not to go back once you leave. Take that step and move forward before it is too late. Also do not waste another minute of your life trying to change an abuser. Do not be afraid to ask for help and advice.

Pathways of prevention. Five ways to help prevent substance abuse include effectively dealing with peer pressure, dealing with life pressure, seeking out help for mental health issues, examining the risk factors, and keeping a well-balanced life. Some more effetive ways, other than drugs, to help relieve stress, are exercising, reading, and volunteering. An additional pathway to drug abuse prevention is education and increased awareness.

Pathways of recovery. After a hunting accident accident that resulted in right leg amputation, the volunteer used his experience to motivate people around him. He has made himself available to different groups of people and has used this experience as a motivational tool. One thing that we all need to remember is that when things happen, we should use those experiences to help other people that are going through similar situations. Just a word of "everything is going to be ok" or "I understand what you are going through" goes a long way. The volunteer has made contact with other people that have gone through similar situations as he has. 


\section{Conclusion}

Provision of opportunity for student counselors-in-training to get inside a trauma experience of another person did increase knowledge of impact of the types of trauma they might encounter as future educators. The research project also fulfilled the role of a needs assessment as participants acquired information from volunteers and then reflected on life influences both before and after trauma experiences that educators could intervene with through support for students. The study supports continuing need for both training and skills development in Trauma Informed Practice as routine with pre-service educator training and professional development training for practicing educators.

\section{References:}

1. Anderson, E.M., Blitz, L.V. \& Saastamoinen, M. (2015). Exploring a school-university model for professional development with classroom staff: Teaching trauma-informed approaches. School-Community Journal, 25 (2), 113-134.

2. Banks, Y. R. B. \& Meyer, J. (2017) Childhood trauma in today's urban classroom: Moving beyond the therapist's office. Journal of Educational Foundations, 30 (1-4), 63-75.

3. Bath, H. (2015). The three pillars of traumawise care: Healing in the other 23 hours. Reclaiming Children \& Youth, 23 (4), p5-11.

4. Becker-Weidman, A. (2009). Effects of early maltreatment on development: A descriptive study using the Vineland Adaptive Behavior Scales-II, Child Welvare, 88(2), 137-161.

5. Bell, H. Limberger, D.Robinson,III, E.M. (2013). Recognizing trauma in the classroom: A practical guide for educators. Childhood Education, May/June, 139-145.

6. Blaustein, M.E. \& Kinniburgh, K.M. (2010). Treating traumatic stress in children and adolescents: How to foster resilience through attachment, self-regulation, and competency. New York: Guildord Press.

7. Day, A. G.;,Somers, C. L.;,Baroni, B. A., West, S. D., Sanders, L. \& Peterson, C. D. (2015). Evaluation of a trauma-informed school intervention with girls in a residential facility school: Student perceptions of school environment. Journal of Aggression, Maltreatment \& Trauma, 24 (10), 1086-1105.

8. Engebretson,K.E. \& Weiss, A.M. (2015). A brave new curriculum: Empowering teachers and students in times of trauma. Curriculum and Teaching Dialogue, 17(1-2), 57-68.

9. Ferentz, L. (2015). Treating self-destruction behaviors in trauma survivors: A clinician's guide.(2nd ed.) New York, NY: Routledge. 
10. Heide, F. J., Mooren, T. M.; \& Kleber, R. J. (2016). Complex PTSD and phased treatment in refugees: a debate piece. European Journal of Psychotraumatology. 7, 1-9.

11. Jenkins, L.N., Fredrick, S.S. \& Wenger, J. (2017). Peer victimization and social-emotional outcomes: The role of teacher and peer support. Aggressive Behavior, 44, 176-184.

12. Langley, A., Santiago, C.D., Rodriguez, A., \& Zelaya, J. (2013). Improving implementation of mental health services for trauma in multicultural elementary schools: Stakeholder persepctives on parent and educator engagement. Journal of Behavioral Health Services and Research, 40 (3), 247-262.

13. Meshcheryakova, K. (2012). Art therapy with orphaned children" dynamics of early relational trauma and repetition compusion. Art Therapy: Journal of the American Art Therapy Association, 29(2), 50 $-59$.

14. Reinbergs, E.J. \& Fefer, S.A. (2017) Addressing trauma in schools:Multitiered service delivery option for practitioners. Psychology in the Schools, 55, 250-263.

15. Shu-chin W. \& Pope, A. (2019) Three-level understanding: recovering self-awareness in the art of critical_thinking. Journal of Thought, 53(1/2). 21-37.

16. Steele, W. \& Malchiodi, C.A. (2012). Trauma-informed practices with children and adolescents. New York NY: Routledge.

17. Thompson, C.V. \& Schwartz, P.J. (2014). A new normal: Young men of color, trauma, and engagement in learning. New Directions for Adult and Continuing Education.144, 40-58.

18. Villenas, S.A. (2018). Here, there, and back again with the social foundations of education: Tracing conocimientos in/toward coalitional journeys. Educational Studies 54(1), 109-113.

19. von der Embse, N. P., Kilgus, S. P. Eklund, K. Ake, E. Levi-Neilsen, S. \& Eckert, T. (2018). Training teachers to facilitate early identification of mental and behavioral health risks. School Psychology Review, 47 (4), 372-384

20. Wamser-Nanney, R. \& Vandenburg, V.R. ( 2013). Empirical support for the definition of a complex event in children and adolescents. Journal of Traumatic Stress (6), 671-678 